\title{
An Assessment of Occupational Safety \& Health Hazards, Health Problems, and Safety Practices in the Operational Environment of Petrol Stations
}

\author{
*Michael Morrison ${ }^{1}$ and Shanomae Rose ${ }^{1}$ \\ ${ }^{1}$ Department of Environmental Studies. Faculty of Earth and Environmental Sciences. University of Guyana - \\ Turkeyen Campus. Greater Georgetown, Guyana. *michealmorrison30@gmail.com.
}

DOI: $10.52377 / O X D F 6608$

Studies have shown that pump attendants are exposed to occupational safety and health hazards, which has health implications. There is also a lack of knowledge amongst pump attendants about key safety measures that can be used to abate these hazards. This study focused on determining BTEX concentrations to which pump attendants are exposed over a forty-hour work week; assessing their knowledge of safety and health hazards, safety practices, and identifying the types of health problems they may have experienced on the job. Using the MiniRAE 3000, BTEX concentrations were measured at six petrol stations in Demerara-Mahaica (Region IV) over five working days. The knowledge and health problems associated with 52 pump attendants were obtained using a structured, interviewer administered questionnaire. An observational checklist was also designed to collect supporting data on daily workplace conditions and practices. At petrol stations A1, A2, B1, B2, C1, and C2, benzene concentrations were found to be 10.17ppm, 7.84ppm, 10.44ppm, 3.99ppm, 9.65ppm, and 5.96ppm respectively, exceeding the ACGIH's TLV-TWA of $0.5 \mathrm{ppm}$. $54 \%$ of pump attendants had poor knowledge of safety and health hazards, whereas $98 \%$ had good knowledge of safety practices. Tiredness, headaches, and lower back pain were reported as the most frequent health problems affecting pump attendants. Binary logistic regression $(p<0.05)$ revealed that gender was a significant predictor of headaches $(p=0.018,95 \% \mathrm{Cl}=0.028-0.718)$ and lower back pain $(\mathrm{p}=0.008,95 \% \mathrm{Cl}=0.011-0.507)$. This study recommends that adequate personal protective equipment and training are needed to safeguard the health and safety of pump attendants.

Keywords: Pump attendants; BTEX concentrations; occupational safety and health 